\title{
Resilience: Examining the Impacts of the Deepwater Horizon Oil Spill on the Gulf Coast Vietnamese American Community
}

\author{
Megha M. Patel ${ }^{1, *}$, Leia Y. Saltzman ${ }^{1}$, Regardt J. Ferreira ${ }^{1,2}$ and Amy E. Lesen ${ }^{3}$ \\ 1 School of Social Work, Tulane University, New Orleans, LA 70112, USA; lsaltzman@tulane.edu (L.Y.S.); \\ rferrei@tulane.edu (R.J.F.) \\ 2 Department of Social Work, University of the Free State, Bloemfontein, South Africa \\ 3 ByWater Institute, Tulane University, New Orleans, LA 70118, USA; alesen@tulane.edu \\ * Correspondence: mpatel@tulane.edu
}

Received: 18 September 2018; Accepted: 18 October 2018; Published: 20 October 2018

\begin{abstract}
The 2010 Deepwater Horizon oil spill (DWH) was one of the largest hydrocarbon disasters in US history. The estimated 5 million barrels of oil that poured into the Gulf of Mexico had a devastating impact on the natural environment, as well as on the livelihoods of communities residing along the coastal region. This paper explores resilience in individuals that identify as Vietnamese, presenting findings from a study of three Gulf Coast communities impacted by the DWH oil spill. A 60-min, in-person survey was administered to a total of 326 residents from the Gulf Coast communities of Port Sulphur, LA, Galliano, LA, and Bayou La Batre, AL. Logistic regression outcome and key predictors models were used to determine the probability of having higher levels of resilience. The results of this study highlight the role of age, education, and racial/ethnic identification in fostering resilience following disaster exposure. Identifying as Vietnamese was associated with a decrease in the odds of achieving above-threshold levels of resilience. This study may be viewed as the foundation from which to further explore the unique risk and protective profiles of the Vietnamese population, particularly in regard to those residing in critically vulnerable and disaster-prone areas.
\end{abstract}

Keywords: resilience; disaster; oil spill; Vietnamese

\section{Introduction}

The 2010 Deepwater Horizon oil spill (DWH) was one of the largest hydrocarbon disasters in US history. An estimated five million barrels of oil spilled into the Gulf of Mexico over a five-month period, reaching the shorelines of the US Gulf Coast, which stretches from Florida to Texas (Devi 2010; McCauley 2010; Schmidt 2010). The oil that poured into the Gulf of Mexico had a devastating impact on the natural environment, as well as on the livelihoods of communities residing along the coastal region. The people living along the Gulf Coast are diverse, as are their experiences in preparing for, responding to, and recovering from disaster.

According to the U.S. Census Bureau (2011), approximately 33\% of the Vietnamese population in the United States lives in the southern region of the country. Beginning around 1975, the Vietnamese community settled in the Gulf Coast region, primarily as refugees from the Vietnam War, resiliently rebuilding their lives in a new land (Tang 2011). Currently, the Vietnamese communities on the Gulf Coast are an integral part of the fishing, agriculture, and oil industries, but are also becoming increasingly active in politics and social issues (Cowley et al. 2012). In the aftermath of Hurricane Katrina, the resilience displayed once again by the Vietnamese community drew much scholarly attention (Leong et al. 2007; VanLandingham 2017). Unfortunately, large-scale disasters have become 
the norm on the Gulf Coast, and communities once again were forced to respond and rebuild following the impact of the DWH oil spill.

This paper explores resilience in individuals that identify as Vietnamese American, presenting findings from a study of three Gulf Coast communities impacted by the DWH oil spill.

\subsection{Resilience}

According to Alexander (2013), the origin of the term "resilience" has had varying but interrelated meanings within the fields of art, literature, science, and engineering. Prior to the twentieth century, the term was primarily used in engineering to refer to the ability of a material to withstand and absorb force. By the 1950s, resilience was being used in developmental psychology and anthropology in the study of children and vulnerability (Alexander 2013). Over time, the meaning of the concept transitioned to notions of equilibrium, stability, and the resistance to shocks (Alexander 2013; Timmerman 1981). The concept of resilience was later adopted by the fields of sociology and human geography, and from there, made the natural alliance to the study of disasters, and how communities prepare and plan for, recover from, and adapt to adverse events (Alexander 2013; Hobfoll et al. 2015; Manyena et al. 2011). While Hobfoll et al. (2015) emphasize resilience as the return to a pre-stressor state, Neenan (2009) argues that resilience is the ability to "self-right" and positively adapt to adversity or change. These nuanced definitions, as well as the notion of relative resilience, are important factors to consider when interrogating the resilience of individuals and communities (Bonanno et al. 2015). Given the multidisciplinary use of the term resilience, reconciling its meaning and conceptualization has proven challenging and continues to be a limitation in its application to research and practice (Alexander 2013).

Resilience is often understood as the relationship between risk and protective factors. Empirical findings suggest risks to resilience include factors such as low socioeconomic status, life stress, minority race, childhood abuse, poor education, poor social support, and past trauma (Brewin et al. 2000). Lauve-Moon and Ferreira (2017) add that factors such as gender, family structure, lack of employment, English as a second language, and low levels of social and emotional support can increase susceptibility to additional stress and harm within a disaster context. Alternatively, protective factors include those in opposition to the identified risks, as well as traits such as a positive outlook, courage, cognitive flexibility, humor, social skills, and spirituality (Bonanno 2004; Neenan 2009). Friborg et al. (2009) argue that resilience is not simply the absence of risk, nor should it be conceptualized in terms of psychopathology. Instead, resilience should be considered as a construct that can be enhanced in individuals and communities through appropriate strategies (Shenesey and Langhinrichsen-Rohling 2015). Understanding how risk and protective factors interact is essential for identifying ways to promote resilience in communities experiencing and responding to disasters.

Within the framework of studying hazards and disasters, resilience has often been conceptualized in terms of community resilience. Community resilience can refer to both how disasters affect members of a particular group and the ways in which communities organize in response to disasters (Norris et al. 2008). Cutter et al. (2014) note that while community resilience has become the frequent model through which to understand disaster preparedness, response, and recovery, there remains little consensus regarding its definition, measurement, and robustness as a tool for understanding complex social systems. Much of the research on disaster resilience has focused on weather-related disasters. However, through a review of 130 disaster events, Picou et al. (2004) found that technological disasters such as oil spills were more psychologically stressful than weather-related disasters. Cheong (2014) notes that hurricanes can be devastating to a community, and can have widespread effects on lives and homes, but that uncertainty for the future is at the heart of oil spills. An event such an oil spill can have longer-term impacts on the economy, ecological system, and health of a community (Webler and Lord 2010). Cheong (2014) describes oil spills as "slow torture". 
Picou et al. (2004) note that the defining characteristic of the aftermath of oil spills and catastrophic technological disasters is a "corrosive community", which is a consistent pattern of chronic impacts to individuals and communities. The most significant factors that contribute to corrosive communities are the mental and physical health of victims, perceptions of governmental or organizational failure, and protracted litigation (Marshall et al. 2003; Picou et al. 2004). Evidence suggests that when an expert or organization tasked with carrying out recovery efforts fails to do so, there is a heightened perception of risk, high levels of psychological distrust, and perceived community damage (Couch 1996; Freudenburg 1993). Likewise, the act of holding organizations and institutions accountable for technological disasters through the litigation process can itself be a trauma (Picou et al. 2004; Strasburger 1999).

Residents of the US Gulf Coast have had to prepare for, respond to, rebuild following, and adapt to repeated disasters. Chinoy (2018) mapped the places in the US where disasters strike repeatedly, and found that the US Gulf Coast experienced a disproportional number of disasters between 2002 and 2017 compared to other parts of the United States. Understanding how risks, such as repeated disasters, affect resilience is essential to supporting communities in the face of adverse events.

\subsection{Vietnamese Community}

One particular community that has had to face repeated displacements and adaptation to adverse events is the Gulf Coast Vietnamese community. The majority of the Vietnamese community living along the Gulf Coast have resided there since the 1970s, arriving as refugees during the Vietnam War (Tang 2011). The Gulf Coast region offered many similarities to Vietnam, such as French influence, the prevalence of Catholicism, and the subtropical climate, and thus came to be one of the most highly concentrated Vietnamese immigrant communities in the US (Cowley et al. 2012). In their resettlement to the US, the Vietnamese brought with them strong cultural ties to Vietnam, and leveraged their strong community ties and entrepreneurship skills to enter the local fishing industry (Bankston III and Zhou 1996). It is estimated that $80 \%$ of Vietnamese Americans in the Gulf Coast are connected to the seafood industry (Ravitz 2010). Federal data also suggests that today one in four shrimpers in the Gulf of Mexico are of Southeast Asian descent (Macchi 2015). The Gulf Coast Vietnamese community's relationship to the fishing industry has served as both an asset and challenge in times of disaster.

Oil spill disasters can be particularly detrimental to shrimpers, as crustaceans and mollusks are especially vulnerable to contamination by polycyclic aromatic hydrocarbons found in crude oil (Law et al. 2002). Public confidence in Gulf seafood was slow to rebuild following the DWH oil spill, and according to estimates from the US Bureau of Ocean Energy Management, the disaster cost the commercial fishing industry between $\$ 94.7$ million and $\$ 1.6$ billion, and close to 9000 jobs in the eight months following the oil spill (Carroll et al. 2016). Among the Gulf Coast Vietnamese community, a study by Ngo et al. (2014) in which the majority of the sample reported working in the seafood industry, the authors found that $59 \%$ reported loss of income, $27 \%$ reported loss of employment, and $12 \%$ reported an inability to pay bills following the DWH oil spill.

While the Vietnamese have become an integral part of the Gulf Coast, their experiences when disasters strike in the region are unique. Scholars argue that factors such as socioeconomic resources, ethnic enclaves, and language barriers can negatively influence resilience in immigrant communities following a disaster (Cutter et al. 2006; Elliot and Pais 2006). However, VanLandingham (2017) found that despite their poor odds for success, following Hurricane Katrina, the Vietnamese community in New Orleans returned to the city more quickly and completely than other groups, their post-disaster health and economic outcomes were better, and their community mobilization efforts were more vigorous. These contradictory findings regarding immigrant communities, resilience, and disasters make further research in this domain important. 


\subsection{Purpose}

The literature suggests there are differences in how disasters affect resilience in individuals and communities, and that in the face of disasters, immigrant communities experience unique challenges and strengths. This paper aims (1) to further explore the relationship between risk and protective factors as it relates to resilience in individuals that identify as Vietnamese, and (2) present findings from a recently completed study from three Gulf Coast communities impacted by the DWH oil spill. It is hypothesized that individuals in the Vietnamese community will have higher levels of resilience than non-Vietnamese individuals.

\section{Materials and Methods}

The data for this study is derived from a survey conducted through the Consortium for Resilient Gulf Communities, established in 2015 with a grant from the Gulf of Mexico Research Initiative (GoMRI) to assess and address the public health, social, and economic impacts of the $2010 \mathrm{DWH}$ oil spill in the Gulf of Mexico region. The purpose of the survey was to investigate the role of social networks, risk perception, preparedness measures, individual resilience, and demographics as predictors of preparedness and resilience for future hydrocarbon events among residents of the Gulf of Mexico. In-person interviews, lasting approximately $60 \mathrm{~min}$, were administered by trained data collectors from Tulane University in three Gulf Coast communities between June and November 2017: Galliano, LA (Lafourche Parish), Port Sulphur, LA (Plaquemines Parish), and Bayou La Batre, AL (Mobile County). The study was conducted with approval from the Tulane University Institutional Review Board (IRB\# 16-997431U).

\subsection{Sampling and Recruitment}

To be eligible for the study, participants had to be 18 years or older, English- or Vietnamese-speaking, and residing in select zip codes in and around either Galliano, Louisiana, Port Sulphur, Louisiana, or Bayou La Batre, Alabama. Recruitment for the study was conducted primarily by Louisiana State University's Public Policy Research Lab (PPRL) through the use of their existing database of households in the Gulf of Mexico region. PPRL sent a total of 4746 English-language recruitment packages in Louisiana and 4272 English- and Vietnamese-language recruitment packages in Alabama via mail to the target communities. Recruitment packages consisted of a recruitment letter with information on the study with both mail-in instructions and a web-link for scheduling an appointment to participate in the study. The study was anonymous, and the research team did not have access to the contact information of study participants. A goal of 100 surveys per site was set by the research team. To reach this goal, recruitment by PPRL was supplemented by snow-ball sampling with the assistance of local community partners.

In Bayou La Batre, AL, the research team partnered with Boat People SOS (BPSOS), a national Vietnamese-American nonprofit community-based organization with branches in the Gulf of Mexico region. The staff of BPSOS completed the training required by the Tulane University IRB and joined the research team as data collectors, primarily recruiting and interviewing Vietnamese-speaking respondents.

\subsection{Procedure}

Individuals contacted through PPRL that expressed an interest in participating in the study were scheduled for 60-min in-person interviews. The research team received a schedule from PPRL, which contained a 4-digit identifier and the last name for each participant. No other identifying information was provided to the research team, and the schedule was destroyed after data collection to ensure participant privacy. Individuals recruited via snow-ball sampling were also given 4-digit identifiers by a member of the research team upon arrival at the designated sites on predetermined days and interviewed the same day. No other identifying information for individuals recruited via snow-ball 
sampling was collected. Vietnamese-speaking individuals in Bayou La Batre, AL were recruited via mail by PPRL and snow-ball sampling via BPSOS.

Surveys were conducted in private meeting rooms within public buildings (e.g., library, medical center). Surveys were administered by data collectors that had completed IRB requirements for conducting research (e.g., Collaborative Institutional Training Initiative (CITI) training), as well as cultural sensitivity and data collection training. Data collection teams consisted of at least one data collector and a data collection supervisor. Verbal informed consent was obtained for all participants prior to beginning the survey. Data collectors administered the surveys using either a handheld tablet computer or a paper-based questionnaire, depending on the participant's preference. Participants were provided with a $\$ 50$ Walmart gift card for their participation in the study. Surveys were collected from 89 participants from Galliano, LA, 95 from Port Sulphur, LA, and 142 participants from Bayou La Batre, AL. The total sample for this study included 326 participants.

\subsection{Measures}

\subsubsection{Resilience}

Resilience was measured using the 10-item Connor Davidson Resilience Scale, which uses a 5-point, self-reporting Likert scale, where 1 indicates "not at all" and 5 indicates "true nearly all the time". The Connor Davidson Resilience Scale has been shown to have high internal consistency, construct validity and test-retest reliability (Connor and Davidson 2003; Fincham et al. 2009; Nrugham et al. 2010). Respondents were asked the following ten questions regarding resilience: (1) I am able to adapt when changes occur; (2) I can deal with whatever comes my way; (3) I try to see the humorous side of things when I am faced with problems; (4) Having to cope with stress can make me stronger; (5) I tend to bounce back after illness, injury, or other hardships; (6) I believe I can achieve my goals, even if there are obstacles; (7) Under pressure, I stay focused and think clearly; (8) I am not easily discouraged by failure; (9) I think of myself as a strong person when dealing with life's challenges and difficulties; and (10) I am able to handle unpleasant or painful feelings like sadness, fear, and anger. A composite score was created by adding responses to the $10 \mathrm{items}$. According to Campbell-Sills et al. (2009), a score of 31.8 is the mean resilience score for the general population; thus, a score of 32 or greater was used to indicate greater levels of resilience in the study sample. Using this benchmark, scores were recoded from the continuous measure of resilience into binary variables in which 0 indicated below-threshold resilience and 1 indicated above-threshold resilience.

\subsubsection{Disaster Experience}

Disaster experience was used as an indicator of risk. Respondents were asked if they were in the Gulf Coast region during six previous disasters-Hurricane Katrina, Hurricane Rita, Hurricane Gustav, Hurricane Ike, and the DWH oil spill. A composite score was created by adding affirmative responses to the six questions (i.e., scale of 0-6). In the current analysis, disaster experience was recoded as a $0 / 1$ binary in which 0 indicated exposure to "none of the events" and 1 indicated exposure to "at least one event".

\subsubsection{Social Network Trust}

A variable assessing trust in one's social network was generated as an indicator of a protective factor. Respondents were asked to list eight people that they might turn to in preparing and responding to a disaster. For each of the eight people listed in their social network, respondents were asked the degree to which they trust each individual, based on a 4-point Likert scale. A composite score for trust was created by averaging the responses, with a mean score of $10.96(\mathrm{SD}=16.35)$. A score greater than the mean indicates greater levels of trust towards one's social network. 


\subsubsection{Control Variables}

In addition to the above measures, the analysis also includes several control variables. Respondents were asked to self-identify their race, based on 14 predetermined categories, with the option to choose multiple races. To compare the Vietnamese population to all other racial groups, race was recoded into a binary variable, in which 0 indicates all other races, and 1 indicates those that identify only as Vietnamese. Age was measured as a self-reported, interval-ratio variable. Gender was a categorical variable (e.g., male; female; other), but no respondents selected a gender other than male or female; thus, the variable was coded as dichotomous with 1 indicating female, and 0 indicating male. Respondents were asked to indicate their education level based on 6 predetermined categories (i.e., less than 12 years; high school diploma; some college; associate's degree; bachelor's degree; graduate degree). The variable for education was recoded into a binary variable where 0 indicated a high school diploma/GED or less, and 1 indicated some college or more. Survey interviews were conducted at three sites: Galliano, LA; Port Sulphur, LA; and Bayou La Batre, AL. Galliano, LA served as the reference group.

\subsection{Statistical Analysis}

Analysis was conducted using STATA (version 13.1). Less than $6 \%$ of respondents $(n=18$; $5.52 \%$ ) were missing responses to all items used in our analysis. As such analysis relied on listwise deletion, multiple imputation was not used to correct for missingness. Descriptive statistics were first conducted to better understand the characteristics of the sample. Next, bivariate analysis was conducted to explore the relationship among main variables of interest. Finally, a series of stepwise logistic regression models were estimated on the total sample. A p-value of less than 0.05 was deemed statistically significant. Continuous variables were checked for skew and kurtosis using 3 and 7 as cut-points respectively. Given there were no violations of normality, variables were not recoded to correct the distribution. This also was done for the ease of interpretability of models.

\section{Results}

\subsection{Characteristics of the Study Sample}

\subsubsection{Total Study Sample}

The sample for the main study had a total of 326 participants, with $24.19 \%(n=75)$ identifying their race as Vietnamese only and $75.81 \%(n=235)$ identifying as another race or ethnicity (see Table 1$)$. The mean age of the total sample was 55.05 years $(\mathrm{SD}=15.80)$ with $61.04 \%(\mathrm{n}=199)$ of participants identifying as female. The majority of the total sample, $61.11 \%(n=198)$, reported having a high school degree or below. Of the total sample, 27.3\% $(n=89)$ were from Galliano, LA, 29.14\% $(n=95)$ were from Port Sulphur, LA, and $43.56 \%(\mathrm{n}=142)$ were from Bayou La Batre, AL.

In regard to the total survey sample, $96.01 \%(n=313)$ reported having experienced at least one of the previous six disasters-Hurricanes Katrina, Rita, Gustav, Ike, Isaac, and/or the Deepwater Horizon oil spill. The majority of respondents, $94.19 \%(n=292)$, reported having prepared for natural disasters, while only $8.79 \%(\mathrm{n}=27)$ reported having prepared for an oil spill disaster. In regard to social networks, $19.94 \%(n=64)$ of the total sample reported that their social network mainly consisted of people that were Vietnamese. The mean trust score of social networks was 10.95 (SD =16.35). At the time of the Deepwater Horizon oil spill, $64.87 \%(n=205)$ of the sample reported being employed, with $22.86 \%(n=48)$ of respondents reporting they lost their job following the oil spill. The sample had a mean resilience score of $30.29(\mathrm{SD}=7.58$ ) based on the Connor-Davidson Resilience Scale, with $47.55 \%$ $(n=155)$ reporting high levels of resilience. 
Table 1. Characteristics of study sample $(\mathrm{N}=326)$.

\begin{tabular}{|c|c|c|}
\hline & \multicolumn{2}{|c|}{$\begin{array}{c}\text { Total } \\
(\mathrm{n}=326)\end{array}$} \\
\hline & n & m (SD)/\% \\
\hline \multicolumn{3}{|l|}{ Race } \\
\hline Vietnamese & 75 & 24.19 \\
\hline All other races & 235 & 75.81 \\
\hline Age & 326 & $55.05(15.80)$ \\
\hline \multicolumn{3}{|l|}{ Gender } \\
\hline Female & 199 & 61.04 \\
\hline Male & 127 & 38.96 \\
\hline \multicolumn{3}{|l|}{ Education Level } \\
\hline High school and below & 198 & 61.11 \\
\hline College and above & 126 & 38.89 \\
\hline \multicolumn{3}{|l|}{ Site } \\
\hline Galliano, LA & 89 & 27.30 \\
\hline Port Sulphur, LA & 95 & 29.14 \\
\hline Bayou La Batre, AL & 142 & 43.56 \\
\hline \multicolumn{3}{|l|}{ Disaster Experience } \\
\hline Not experienced a disaster & 13 & 3.99 \\
\hline Experienced a disaster & 313 & 96.01 \\
\hline \multicolumn{3}{|l|}{ Ever Prepared for Natural Disaster } \\
\hline Yes & 292 & 94.19 \\
\hline No & 18 & 5.81 \\
\hline \multicolumn{3}{|l|}{ Ever Prepared for Oil Spill Disaster } \\
\hline Yes & 27 & 8.79 \\
\hline No & 280 & 91.21 \\
\hline \multicolumn{3}{|l|}{ Social Network Type } \\
\hline Mostly Vietnamese & 64 & 19.94 \\
\hline Some Vietnamese & 15 & 4.67 \\
\hline No Vietnamese & 242 & 75.39 \\
\hline Social Network Trust & 326 & $10.95(16.35)$ \\
\hline \multicolumn{3}{|l|}{ Employed at time of DWH oil spill } \\
\hline Yes & 205 & 64.87 \\
\hline No & 111 & 35.13 \\
\hline \multicolumn{3}{|l|}{ Lost job due to DWH oil spill } \\
\hline Yes & 48 & 22.86 \\
\hline No & 162 & 77.14 \\
\hline Connor Davidson Resilience Scale & 326 & $30.29(7.58)$ \\
\hline Total & 326 & 100.00 \\
\hline
\end{tabular}

\subsubsection{Sample That Identified as Vietnamese}

Of the sample that identified as Vietnamese $(n=75)$, the mean age was slightly younger than the total sample at 53.39 years $(S D=16.21)$, with $37.33 \%(n=28)$ of Vietnamese participants identifying as female. Nearly all Vietnamese participants in the sample $(98.67 \%, \mathrm{n}=74)$ were from the Bayou La Batre, AL site. The mean trust score of social networks within the Vietnamese sample was $27.42(\mathrm{SD}=22.19)$, indicating higher levels of trust than the total sample. However, participants that identified as Vietnamese had a mean Connor-Davidson Resilience Scale score of $26.29(\mathrm{SD}=6.95)$, lower than the total sample.

\subsection{Stepwise Logistic Regression}

Table 2 illustrates the three logistic regression models of the total survey sample. Model 1 included only demographic control variables, which includes (a) age, (b) racial identity (coded $1=$ Vietnamese, $0=$ non-Vietnamese), $(\mathrm{c})$ gender (coded $1=$ female, $0=$ male), $(\mathrm{d})$ education level (coded $1=$ college or more, 0 = high school diploma/GED or less), and (e) site (Galliano as reference). Model 2 introduces 
our proxy for risk factors-disaster experience (coded $1=$ experience with at least one disaster, $0=$ no experience); and Model 3 introduces our proxy for protective factors-trust in social network (with higher scores indicating greater trust of social networks).

At $p<0.05$, each of the three models is statistically significant when predicting the probability of higher resilience. All three models accounted for approximately $11 \%$ of the variance in resilience scores. The addition of risk and protective factors only slightly increased the amount of variance explained from the reference model.

Table 2. Stepwise logistic regression predicting resilience $(\mathrm{N}=308)$.

\begin{tabular}{ccccccc}
\hline & \multicolumn{2}{c}{ Model 1 } & \multicolumn{2}{c}{ Model 2 } & \multicolumn{2}{c}{ Model 3 } \\
\cline { 2 - 7 } & OR & SE & OR & SE & OR & SE \\
\hline Age & $1.02^{*}$ & 0.01 & $1.02 *$ & 0.01 & $1.02 *$ & 0.01 \\
Vietnamese & $0.20^{* * *}$ & 0.09 & $0.19^{* * *}$ & 0.08 & $0.18^{* * *}$ & 0.09 \\
Female & 0.83 & 0.21 & 0.83 & 0.21 & 0.83 & 0.21 \\
College or more & $1.83 *$ & 0.49 & $1.81^{*}$ & 0.49 & $1.81 *$ & 0.49 \\
Site 1 & & & & & & \\
Port Sulphur, LA & 0.66 & 0.21 & 0.66 & 0.21 & 0.65 & 0.21 \\
Bayou La Batre, AL & 0.85 & 0.30 & 0.84 & 0.29 & 0.85 & 0.30 \\
Disaster Experience & & & 0.64 & 0.45 & 0.65 & 0.46 \\
Social Net. Trust & & & & & 1.00 & 0.01 \\
$X^{2}$ & 48.42 & & 48.84 & & 48.93 & \\
df & 6 & & 7 & & 8 & \\
$\mathrm{R}^{2}$ & 0.11 & & 0.11 & & 0.11 & \\
\hline
\end{tabular}

OR odds ratio, SE standard error. ${ }^{*} p<0.05,{ }^{* * *} p<0.001 .{ }^{1}$ Site has “Galliano, LA" as reference category.

\subsubsection{Model 1: Control Variables Only}

Age, race, and college education were statistically significant. Each additional yearly increase in age is associated with a $2 \%$ increase in the odds of reporting above threshold levels of resilience. Identifying as Vietnamese was associated with a 20\% reduction in the odds of reporting above threshold levels of resilience as compared to odds of respondents in other racial/ethnic groups. Respondents with a college education or more reported an $83 \%$ increase in the odds of reporting above-threshold levels of resilience, compared to those with a high school education/GED or less. Gender and site were not significant predictors of resilience in this model.

\subsubsection{Model 2: Disaster Experience}

The pattern of significance remains relatively unchanged with age, race, and college education all remaining statistically significant in this model. Gender, site, and disaster experience were not significant predictors of resilience in Model 2.

\subsubsection{Model 3: Social Network Trust}

In the final model, the pattern of significance remained the same as in Models 1 and 2, with age, race, and college education being statistically significant. Gender, site, disaster experience, and social network trust were not significant predictors of resilience in Model 3.

\section{Discussion}

This study contributed to the scant literature available on resilience among the Vietnamese community in the US as it relates to disasters. The results of this study highlight the role of age, education, and racial/ethnic identification in fostering resilience following disaster exposure. In all three models, identifying as Vietnamese was associated with a decrease in the odds of achieving above threshold levels of resilience; this relationship held while accounting for disaster exposure and trust in support networks (two proxies for risk and protective factors). Given the stability of this 
relationship, we suggest that the Vietnamese community in the area of Bayou La Batre, Alabama is particularly vulnerable in disaster contexts. While our models did not identify the specific factors that contribute to that vulnerability, previous literature on immigrant communities in the US and disasters suggest factors such as limited English proficiency, social and physical isolation, lack of bureaucratic acculturation, differences in communication styles, and nontraditional family structures may contribute to difficulties in disaster recovery (Fothergill et al. 1999; Kaplan and Huynh 2008; Mathew and Kelly 2008; Seidenberg 2005; Shui-Thornton et al. 2007; Vielman 2005). A qualitative study of Southeast Asian immigrants in Bayou La Batre, AL following Hurricane Katrina identified sociocultural barriers of (1) language, literacy, and communication; (2) cultural differences in help-seeking; (3) difficulty navigating the disaster recovery bureaucracy; and (4) a lack of leadership as hindering recovery efforts for the community (Nguyen and Salvesen 2014). Exploring how these and other factors may contribute to risks to resilience in the Vietnamese community in the Gulf Coast following a technological disaster are needed.

Similarly, our models did not identify significant factors that buffered the risks associated with exposure to disasters. We suggest that deeper exploration into the unique protective factors for Vietnamese communities is warranted. Nguyen and Salvesen (2014) found that the Southeast Asian community in Bayou La Batre, AL identified trust, cooperation, and collaboration as factors that aided in recovery following Hurricane Katrina. Likewise, VanLandingham (2017) found the Vietnamese community in New Orleans displayed greater resilience following Hurricane Katrina, compared to other groups. However, it is possible that other factors may be influencing the opposite findings in this study, such as the fact that Hurricane Katrina was a very different kind of disaster to the coercive aspects of the DWH oil spill. There may be key differences between the Bayou La Batre and New Orleans Vietnamese communities that affect disaster resilience that need to be identified and studied further.

To assist immigrant communities post-disaster, it is imperative that said communities be integrated into local and regional disaster mitigation and disaster recovery planning approaches. Including these communities in planning for future disasters may create a greater sense of situational awareness about disaster risk, and more importantly may allow community members to identify crucial and lifeline resources for successful disaster preparedness, response and recovery. As Ferreira et al. (2018) note, strengths-based, as well as deficit-based approaches are necessary for identifying risk and protective factors for disaster resilience. Mathew and Kelly (2008) recommend, for example, that municipalities "involve ethnic and community organizations in disaster planning", citing the important roles these groups played in response, evacuation, and distribution of food and medical aid during the Hurricane Katrina disaster, which then prompted participation and consultation of members of the Vietnamese-American and Latino communities in planning and drills for future evacuation and disaster recovery in the New Orleans region.

While this study offers important insights about resilience in the Vietnamese community of the US Gulf Coast following the DWH oil spill, further research is needed to understand why levels of resilience are lower in this community compared to others.

\section{Limitations}

There are several important limitations to note in this study. Firstly, our exploration focuses on a specific demographic population in the Gulf Coast-Vietnamese communities. As such, these findings should be interpreted with caution and not generalized to other racial/ethnic minority or immigrant groups. The second is a limitation in measurement, namely that our model cannot account for the variety of risk and protective factors that may influence the process of adaptation and resilience or the unique cultural variations in risk and protective profiles that may be particularly salient for Vietnamese communities in the US. In addition, our disaster exposure indicator does not account for the severity of exposure, and in fact only a small proportion of our sample (approximately $4 \%$ ) had never previously experienced a disaster, potentially missing some of the nuances of exposure that may 
influence the process of adaptation and resilience. Furthermore, the cross-sectional nature of our data does not account for variability over time. More specifically, this study took place seven years after the DWH oil spill, thus focuses on long-term impacts and may not accurately reflect beliefs and behaviors experienced in the direct aftermath of the disaster. A final limitation to note is that of the measurement of resilience itself. As Weichselgartner and Kelman (2015) note, resilience is a multifaceted concept, one that cannot be easily quantified through indices and scales. Thus, future studies should consider social complexities and contexts that inform and contribute to understandings of resilience.

Despite these limitations, the results of this study offer a preliminary step in exploring the unique experiences of racial/ethnic minority and immigrant groups that are traditionally underrepresented in the disaster literature, and specifically the literature focusing on hydrocarbon disaster recovery. While disaster exposure and trust in social networks were not significant predictors in our models, we expect that more robust accounting for risk and protective factors in future research would give a more holistic picture about the experiences of resilience among traditionally underrepresented populations. This study may be viewed as the foundation from which to further explore the unique risk and protective profiles of the Vietnamese population, particularly in regard to those residing in critically vulnerable and disaster-prone areas. Identifying the factors that buffer risk will be essential for building stronger communities and fostering positive adaptation in the wake of large-scale disasters.

\section{Conclusions}

This study offers evidence of the relationship between disasters, resilience, and immigrant communities, presenting findings from a study of three Gulf Coast communities impacted by the DWH oil spill. The findings suggest that people that identify as Vietnamese had lower levels of resilience when compared to other groups. However, further research is needed to determine why such differences exist. Finding effective resilience strategies to better support communities in their preparation, response, recovery, and adaptation to adverse events is critical, particularly on the Gulf Coast, where repeat disasters have become the norm.

Author Contributions: Conceptualization, M.P., L.S., R.F., A.L.; Methodology, R.F. and A.L.; Formal Analysis, L.S. and M.P.; Investigation, R.F., A.L., M.P.; Resources, R.F. and A.L.; Writing一Original Draft Preparation, M.P.; Writing-Review \& Editing, M.P., L.S., R.F., and A.L.; Visualization, M.P.; Supervision, R.F., A.L., and L.S.; Project Administration, R.F. and A.L.; Funding Acquisition, R.F. and A.L.

Funding: This research was funded by a grant from The Gulf of Mexico Research Initiative [231501-00]. Data are publicly available through the Gulf of Mexico Research Initiative Information \& Data Cooperative (GRIIDC) at https://data.gulfresearchinitiative.org.

Acknowledgments: The authors wish to thank our collaborators on the Consortium for Resilient Gulf Communities project, as well as our Tulane University data collection team. Special thanks to our partner organizations in the three communities where we collected data, and to the residents of Louisiana and Alabama who participated in this research.

Conflicts of Interest: The authors declare no conflict of interest.

\section{References}

Alexander, David E. 2013. Resilience and disaster risk reduction: An etymological journey. Natural Hazards and Earth System Sciences 13: 2702-16.

Bankston III, Carl, and Min Zhou. 1996. Go fish: The Louisiana Vietnamese and ethnic entrepreneurship in an extractive industry. National Journal of Sociology 10: 37-55.

Bonanno, George A. 2004. Loss, trauma, and human resilience: Have we underestimated the human capacity to thrive after extremely aversive events? American Psychologist 59: 20-28. [CrossRef] [PubMed]

Bonanno, George A., Sara Romero, and Sarah I. Klein. 2015. The temporal elements of psychological resilience: An integrative framework for the study of individuals, families, and communities. Psychological Inquiry 26: 39-169. [CrossRef] 
Brewin, Chris R., Bernice Andrews, and John D. Valentine. 2000. Meta-analysis of risk factors for post-traumatic stress disorder in trauma-exposed adults. Journal of Counseling and Clinical Psychology 68: 748-66. [CrossRef]

Campbell-Sills, Laura, David R. Forde, and Murray B. Stein. 2009. Demographic and childhood environmental predictors of resilience in a community sample. Journal of Psychiatric Research 42: 1007-12. [CrossRef] [PubMed]

Carroll, Michael, Brad Gentner, Sherry Larkin, Kate Quigley, Nicole Perlot, Lisa Dehner, and Andrea Kroetz. 2016. An Analysis of the Impacts of the Deepwater Horizon Oil Spill on the Gulf of Mexico Seafood Industry; New Orleans: U.S. Department of the Interior, Bureau of Ocean Energy Management, Gulf of Mexico OCS Region.

Cheong, Sang-Wook. 2014. From frequent hurricanes to the Deepwater Horizon oil spill in coastal Louisiana: The impact of regulatory change. Ecology and Society 19: 29-35. [CrossRef]

Chinoy, Sahil. 2018. The Places in the U.S. Where Disaster Strikes Again and Again. The New York Times. Available online: https:/ /www.nytimes.com/interactive/2018/05/24/us/disasters-hurricanes-wildfiresstorms.html?mtrref=undefined (accessed on 23 July 2018).

Connor, Kathryn, and Jonathan R. T. Davidson. 2003. Development of a new resilience scale: The Connor Davidson resilience scale. Depression and Anxiety 18: 76-82. [CrossRef] [PubMed]

Couch, Stephen R. 1996. Environmental contamination, community transformation and the Centralia Mine Fire. In The Long Road to Recovery: Community Response to Industrial Disaster. Edited by J. Mitchell. New York: United Nations University Press, pp. 60-84.

Cowley, Amanda D., Mark J. Schafer, and Troy Blanchard. 2012. Racial and Ethnic Groups in the Gulf of Mexico Region: Vietnamese. Baton Rouge: LSU AgCenter.

Cutter, Susan L., Christopher T. Emrich, Jerry T. Mitchell, Bryan J. Boruff, Melanie Gall, Mathew C. Schmidtlein, Christopher G. Burton, and Ginni Melton. 2006. The long road home: Race, class, and recovery from Hurricane Katrina. Environment 48: 8-20. [CrossRef]

Cutter, Susan L., Kevin D. Ash, and Christopher T. Emrich. 2014. The geographies of community disaster resilience. Global Environmental Change 29: 65-77. [CrossRef]

Devi, Sharmila. 2010. Anger and anxiety on the Gulf Coast. The Lancet 376: 503-4. [CrossRef]

Elliot, James R., and Jeremy Pais. 2006. Race, class, and Hurricane Katrina: Social differences in human responses to disaster. Social Science Research 35: 295-321. [CrossRef]

Ferreira, Regardt J., Frederick Buttell, and Katie Elmhurst. 2018. The Deepwater Horizon oil spill: Resilience and growth in the aftermath of postdisaster intimate partner violence. Journal of Family Social Work 21: 22-44. [CrossRef]

Fincham, Dylan S., Dan J. Stein, Lucas Korthals Altes, and Soraya Seedat. 2009. Posttraumatic stress disorder symptoms in adolescent: Risk factors versus resilience moderation. Comprehensive Psychiatry 50: 193-99. [CrossRef] [PubMed]

Fothergill, Alice, Enrique G. M. Maestas, and JoAnne DeRouen Darlington. 1999. Race, ethnicity and disasters in the United States: A review of the literature. Disasters 23: 156-73. [CrossRef] [PubMed]

Freudenburg, William. 1993. Risk and recreancy: Weber, the division of labor, and the rationality of risk perceptions. Social Forces 71: 909-32. [CrossRef]

Friborg, Oddgeir, Odin Hjemdal, Monica Martinussen, and Jan H. Resenvinge. 2009. Empirical support for resilience as more than the counterpart and absence of vulnerability and symptoms of mental disorder. Journal of Individual Differences 30: 138-51. [CrossRef]

Hobfoll, Stevan E., Natalie R. Stevens, and Alyson K. Zalta. 2015. Expanding the science of resilience: Conserving resources in the aid of adaptation. Psychological Inquiry 26: 174-80. [CrossRef] [PubMed]

Kaplan, Aaron S., and Uyen Kim Huynh. 2008. Working with Vietnamese Americans in disaster. In Ethnocultural Perspectives on Disaster and Trauma. Edited by Anthony J. Marsella, Jeanette L. Johnson, Patricia Watson and Jan Gryczynski. New York: Springer, pp. 321-49. ISBN 978038773285.

Lauve-Moon, Katie, and Regardt J. Ferreira. 2017. An exploratory investigation: Postdisaster predictors of intimate partner violence. Clinical Social Work Journal 45: 124-35. [CrossRef]

Law, Robin J., Kelly Carole, Kerry Baker, Jacqueline Jones, Alistair D. McIntosh, and Colin F. Moffat. 2002. Toxic equivalency factors for PAH and their applicability in shellfish pollution monitoring studies. Journal of Environmental Monitoring 4: 383-88. [CrossRef] [PubMed] 
Leong, Karen J., Chris Airriess, Wei Li, Angela Chia-Chen Chen, and Verna M. Keith. 2007. Resilient history and the rebuilding of a community: The Vietnamese American community in New Orleans East. The Journal of American History 94: 770-79. [CrossRef]

Macchi, Victoria. 2015. Half a World Away, Vietnamese Build Lives on the American Bayou. VOA. Available online: https:/ / projects.voanews.com/all-over-the-map/vietnamese-bayou/ (accessed on 23 July 2018).

Manyena, Siambabala Bernard, Geoffrey G. O’Brien, Paul O'Keefe, and John Rose. 2011. Disaster resilience: A bounce back or bounce forward ability? Local Environment: The International Journal of Justice and Sustainability 16: 417-24.

Marshall, Brent K., J. Steven Picou, and Duane C. Gill. 2003. Terrorism as disaster: Selected commonalities and long-term recovery for 9/11 survivors. Research in Social Problems and Public Policy 11: 73-96.

Mathew, Ann Bessie, and Kimiko Kelly. 2008. Disaster Preparedness in Urban Immigrant Communities: Lessons from Recent Catastrophic Events and Their Relevance to Latino and Asian Communities in Southern California. Los Angeles: Tomas Rivera Policy Institute and Asian Pacific American Legal Center.

McCauley, Linda A. 2010. Environments and health: Will the BP oil spill affect our health? American Journal of Nursing 110: 54-56. [CrossRef] [PubMed]

Neenan, Michael. 2009. Developing Resilience: A Cognitive-Behavioral Approach. New York: Routledge.

Ngo, Dung, Judith L. Gibbons, Grace Scire, and Daniel Le. 2014. Mental health needs in Vietnamese American Communities affected by the gulf oil spill. Psychology 5: 109-15. [CrossRef]

Nguyen, Mai Thi, and David Salvesen. 2014. Disaster recovery among multiethnic immigrants: A case study of Southeast Asians in Bayou La Batre (AL) after Hurricane Katrina. Journal of the American Planning Association 80: 385-96. [CrossRef]

Norris, Fran H., Susan P. Stevens, Betty Pfefferbaum, Karen F. Wyche, and Rose L. Pfefferbaum. 2008. Community resilience as a metaphor, theory, set of capacities, and strategy for disaster readiness. American Journal of Community Psychology 41: 127-50. [CrossRef] [PubMed]

Nrugham, Latha, Are Holen, and Anne Mari Sund. 2010. Association between attempted suicide, violent life events, depressive symptoms and resilience in adolescents and young adults. The Journal of Nervous and Mental Disease 198: 121-36. [CrossRef] [PubMed]

Picou, J. Steven, Brent K. Marshall, and Duane Gill. 2004. Disaster, litigation, and the corrosive community. Social Forces 82: 1493-522. [CrossRef]

Ravitz, Jessica. 2010. Vietnamese Fishermen in Gulf Fight to Not Get Lost in Translation. CNN.com. Available online: http:/ / www.cnn.com/2010/US/06/24/vietnamese.fishermen.gulf.coast/index.html (accessed on 23 July 2018).

Schmidt, Charles W. 2010. Between the devil and the deep blue sea: Dispersants in the Gulf of Mexico. Environmental Health Perspectives 118: A338-44. [CrossRef] [PubMed]

Seidenberg, Jennifer. 2005. Cultural Competency in Disaster Recovery: Lessons Learned from the Hurricane Katrina Experience for Better Serving Marginalized Communities. University of California, Berkeley School of Law website. Available online: https://www.law.berkeley.edu/library/resources/disasters/Seidenberg.pdf (accessed on 20 October 2018).

Shenesey, Jessica W., and Jennifer Langhinrichsen-Rohling. 2015. Perceived resilience: Examining impacts of the Deepwater Horizon oil spill one-year post-spill. Psychological Trauma: Theory, Research, Practice, and Policy 7: 252-58. [CrossRef] [PubMed]

Shui-Thornton, Sharyne, Joseph Balabis, Kristen Senturia, Aracely Tamayo, and Mark Oberle. 2007. Disaster preparedness for limited English proficient communities: Medical interpreters as cultural brokers and gatekeepers. Public Health Reports 122: 466-71. [CrossRef] [PubMed]

Strasburger, Larry H. 1999. The litigant-patient: Mental health consequences of civil litigation. Journal of the American Academy of Psychiatry Law 27: 203-11.

Tang, Eric. 2011. A gulf unites us: The Vietnamese Americans of Black New Orleans East. American Quarterly 63: 117-49. [CrossRef]

Timmerman, Peter. 1981. Vulnerability, Resilience and the Collapse of Society: A Review of Models and Possible Climatic Applications. Toronto: Institute for Environmental Studies, University of Toronto.

U.S. Census Bureau. 2011. The Vietnamese Population in the United States: 2010; Atlanta: U.S. Census Bureau.

VanLandingham, Mark J. 2017. Weathering Katrina: Culture and Recovery among Vietnamese Americans. New York: Russell Sage Foundation. 
Vielman, K. 2005. Thousands in the Gap: Exposing the Needs the Underserved Asian/Pacific American Community in Hurricane Katrina \& Rita. Houston: Asian/Pacific American Heritage Association.

Webler, Thomas, and Fabienne Lord. 2010. Planning for the human dimensions of oil spills and spill response. Environmental Management 45: 723-38. [CrossRef] [PubMed]

Weichselgartner, Juergen, and Ilan Kelman. 2015. Geographies of resilience: Challenges and opportunities of a descriptive concept. Progress in Human Geography 39: 249-67. [CrossRef] 